\title{
Article \\ Classification of Geomembranes as Raw Material for Defects Reduction in the Manufacture of Biodigesters Using an Artificial Neuronal Network
}

\author{
Rocio Camarena-Martinez ${ }^{1}$, Rocio A. Lizarraga-Morales ${ }^{2, *} \mathbb{D}$ and Roberto Baeza-Serrato ${ }^{1}$ \\ 1 Departamento de Estudios Multidisciplinarios, División de Ingenierías, Campus Irapuato-Salamanca, \\ Universidad de Guanajuato, Yuriria 38944, Guanajuato, Mexico; r.camarenamartinez@ugto.mx (R.C.-M.); \\ r.baeza@ugto.mx (R.B.-S.) \\ 2 Departamento de Arte y Empresa, División de Ingenierías, Campus Irapuato-Salamanca, Universidad de \\ Guanajuato, Salamanca 36885, Guanajuato, Mexico \\ * Correspondence: ra.lizarragamorales@ugto.mx
}

Citation: Camarena-Martinez, R.; Lizarraga-Morales, R.A.;

Baeza-Serrato, R. Classification of

Geomembranes as Raw Material for

Defects Reduction in the Manufacture of Biodigesters Using an Artificial Neuronal Network. Energies 2021, 14 , 7345. https://doi.org/10.3390/ en14217345

Academic Editor: Jeeban Poudel

Received: 8 September 2021

Accepted: 31 October 2021

Published: 4 November 2021

Publisher's Note: MDPI stays neutral with regard to jurisdictional claims in published maps and institutional affiliations.

Copyright: (c) 2021 by the authors. Licensee MDPI, Basel, Switzerland. This article is an open access article distributed under the terms and conditions of the Creative Commons Attribution (CC BY) license (https:// creativecommons.org/licenses/by/ $4.0 /)$.

\begin{abstract}
Recently, biodigesters have attracted much attention as an efficient alternative for energy generation and organic waste treatment. The final performance of a biodigester depends heavily on the quality of its building process and the selection of its raw material: the geomembrane. The geomembrane is the coat that covers the biodigester used to control the migration of fluids. Therefore, the selection of the proper geomembrane, in terms of thickness, resistance, flexibility, etc., is fundamental. Unfortunately, there are no studies for the selection of geomembranes, and usually, it is an empirical process performed by workers based on their own experience. Such empirical selection might be inaccurate, limited, inconvenient, and even dangerous. In order to assist workers during the building process of a biodigester, this study proposes the use of an Artificial Neural Network (ANN) to classify a geomembrane as appropriate or not appropriate for the manufacture of a biodigester. The ANN is trained with a database built from qualitative and quantitative evaluations of different characteristics of geomembranes. The results indicate that the proposed ANN classifies the most suitable geomembranes with a $99.9 \%$ success rate. The proposed ANN becomes a reliable tool that contributes to the quality and safety of a biodigester.
\end{abstract}

Keywords: artificial intelligence; artificial neural network; biodigester; geomembrane; quality; raw material; thermofusion process

\section{Introduction}

The national and international energy crisis is a latent risk, perhaps imminent, given the depletion of conventional oil and the high prices of hydrocarbons. Furthermore, oil and gas could be exhausted within the next 50 years, while coal reserves can only last for the next 115 years based on the current rate of exploitation [1]. Currently, it is important to explore other sources of energy, especially if they are sustainable. Biodigesters have received a lot of attention due to their usage as a renewable source of energy. The main function of biodigesters is to capture methane $(\mathrm{CH} 4)$ emissions by biologically converting organic waste into biogas [2]. Biogas is a renewable fuel produced by the anaerobic digestion of biodegradable organic waste, and it can be used to generate electrical or thermal energy [3].

Biodigesters shall be constructed with the higher standards of quality because it can be dangerous and costly if there are failures in them. One of the factors directly reflected in the quality of the biodigester is the selection of geomembranes. The geomembrane is the raw material of the biodigester (Figure 1). It is defined as a coating or synthetic barrier of very low permeability used to control migration of fluids (liquids or vapors) [4]. This coating covers and protects the entire biodigester. The high-density polyethylene (HDPE) 
geomembrane is the most used geomembrane in the world due to its advantages such as low permeability coefficient and low cost of production [5].

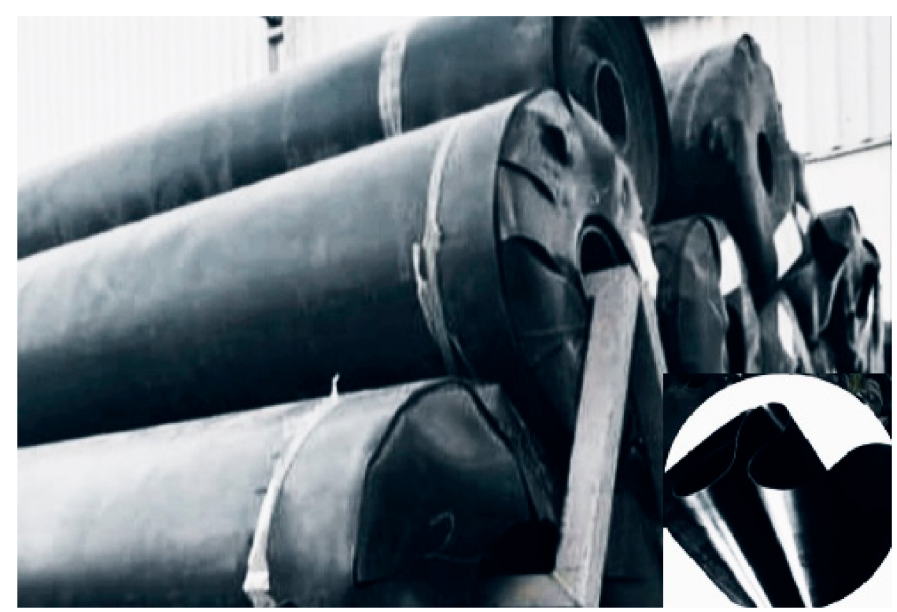

Figure 1. Geomembrane used in the manufacture of biodigesters.

There are different types of biodigesters, however, according to the General Diagnosis of the Situation of Biodigestion Systems in Mexico, presented by the federal bureau of agriculture, animal breeding and rural development (SAGARPA), $94.2 \%$ of biodigesters in Mexico are of the anaerobic lagoon type [6] (See Figure 2). As stated by such report, it is estimated that a high number of these biodigesters are not working due to leaks in the geomembranes. Unfortunately, the user is not able to solve such a problem since it is directly related to the manufacturing of the biodigester [6].

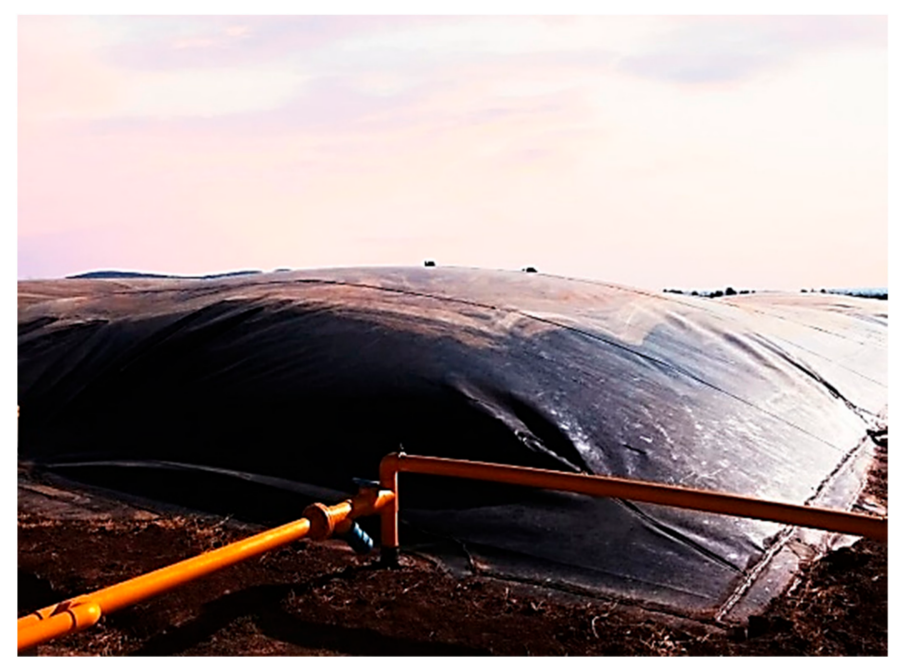

Figure 2. Lagoon biodigester.

One of the most important steps in the manufacturing of a biodigester is the thermofusion operation. This step consists of heating and melting the geomembrane with special tools that meld two surfaces in the biodigester. This process, if it is not performed correctly with the appropriate geomembrane, might generate brittle joints that lead to leaks. These leaks can cause economic losses for customers and endanger the construction personnel. Therefore, the selection of the proper geomembrane for the specific type and size of the biodigester is fundamental and will facilitate the thermofusion process, in addition to guaranteeing its durability and mechanical resistance.

Usually, in Mexican companies that build biodigesters, the selection of a geomembrane is based on the experience of the workers, which leads to an empirical manufacture that is susceptible to errors. The range of possibilities that exists in the market for the selection of 
geomembranes is wide, and the study of their behavior and suitability for the manufacture of biodigesters is limited. Problems such as wear, cracks, poor resistance, brittleness, may arise if the selection is not adequate. In order to choose a geomembrane, factors such as the type of biodigester, size, composition, homogeneity, and resistance must be considered. With the foregoing, we can understand that it is necessary to use techniques that provide a robust analysis of the most suitable geomembranes as raw material for the construction of a biodigester.

The proper selection of raw materials is one of the stages of quality control. Nowadays, different industries recognize that quality control needs to be more and better integrated into its manufacturing processes. With the development of industrial automation, the use of machine learning (ML) techniques for the attention of different stages of quality control has become more popular. For example, we can find a k-nearest neighbor method (KNN) [7] for the classification of knot defect types, rule-based systems [8] for defect detection on patterned textiles, optimization algorithms such as Particle Swarm Optimization (PSO) [9], and artificial neural networks (ANN) [10] for the classification of textile polymer composites, among many other techniques. According to Amor et al. [10], ANN-based approaches receive significant consideration as they provide better prediction accuracy.

Different industries have explored the use of artificial neural networks (ANNs) for the selection of their raw materials used in production, which are closely related to the quality of their final products. De Paula et al. [11] proposed the use of ANNs for the classification of raw material for tea producers to ensure a high quality of the final product. Mellit et al. [12] developed a deep neural network for classification of diseased crops in order to select the best crops to be used for food products. Essid et al. [13] adopted a model using a deep neural network architecture for the classification of metal boxes used as raw materials in the food industry. Gomez et al. [14] presented a methodology based on multilevel and probabilistic networks to classify clays used as raw materials in the pastes for construction, with the purpose of reducing rejection rates in products. Singh et al. [15] evaluated the raw materials in the ferrochrome production used in the manufacture of steels. The authors identified that raw materials play a vital role, because an optimized combination could improve the kiln performance and minimize energy consumption. Zhu et al. [16] investigated the process of dry-cured ham from the raw material to the curing period, where they evaluated protein degradation and quality changes during the process using an ANN. Kulisz et al. [17] created a neural network model that can be used to directly predict the state of groundwater quality used as the main source of water supply for people.

Regarding the studies of applications of ANN for geomembranes and biodigesters, Kumari et al. [18] developed an ANN model considering different shapes of the geomembrane to predict the leak rate in landfills. Abuel-Naga and Bouazza [19] used an artificial intelligence (AI) procedure called the General Data Management Method to predict the rate of liquid leakage in geomembranes used in waste containment facilities. However, the authors recommend increasing the studies to improve predictions. Mandal et al. [20] predicted the performance and emission characteristics of a dual-fuel compression-ignition engine, using an ANN, varying the biogas mass flow rate. Frankowski et al. [21] created a deep neural network model, which predicted methane gas production from floriculture residues. Idris et al. [22] evaluated the performance of three biodigesters of different models for the production and optimization of biogas using an ANN integrated with a genetic algorithm. Tabarquino et al. [23] estimated the volume of a balloon biodigester using a backpropagation ANN. As it can be seen, there is extensive literature on the use of ANN for the selection of raw materials in other industrial processes. However, in the context of biodigesters, ANN have only been explored for the study of the behavior and performance of the biodigesters. As far as the authors know, the use of ANN for the analysis of different types of geomembranes as raw material used in the manufacture of biodigesters has not been explored in any way. 
In this paper, an ANN to determine if a geomembrane is suitable for the manufacturing process of a given biodigester, is proposed. Depending on the characteristics of the geomembrane and the size of the biodigester, an ANN determines if the given geomembrane can be used for the thermofusion process and, therefore, diminish the errors and improve the durability and mechanical resistance of the biodigester. The contributions of this manuscript are twofold. First, considering that a database for this specific problem does not exist, a database is built from the definition of raw material requirements and the conceptualization of the variables given by experts in biodigester manufacturing and validated by physical tests. This database will detail the geomembranes that may be appropriate to reduce defects in the thermofusion operation for a given biodigester. Second, an ANN to evaluate the suitability of a given geomembrane as raw material for a given biodigester, is proposed.

The rest of the paper is organized as follows: Section 2 describes the methodology followed to build the database. It describes the process followed for the definition of the raw material requirements and the quantitative validation. Additionally, the methodology followed to select the best architecture for the ANN is defined. The performance results of the ANN and how the optimal parameters were established are discussed in Section 3. Finally, conclusions are drawn in Section 4.

\section{Materials and Methods}

The methodology followed in this study is described in this section. The main goal of this proposal is to replace the experience of the operators by creating an ANN that evaluates if a given geomembrane might be used for the manufacture of lagoon biodigesters. The steps that were carried out are described below:

Stage 1. Definition of material requirements: obtain through interviews quality requirements for high-density polyethylene geomembranes as raw material of biodigesters.

Stage 2. Conceptualization of the variables: analyze the data of the selected requirements and validate them through a physical test. Build a database.

Stage 3. Development of an ANN able to classify suitable geomembranes for the construction of biodigesters.

The stages described above are illustrated in Figure 3.

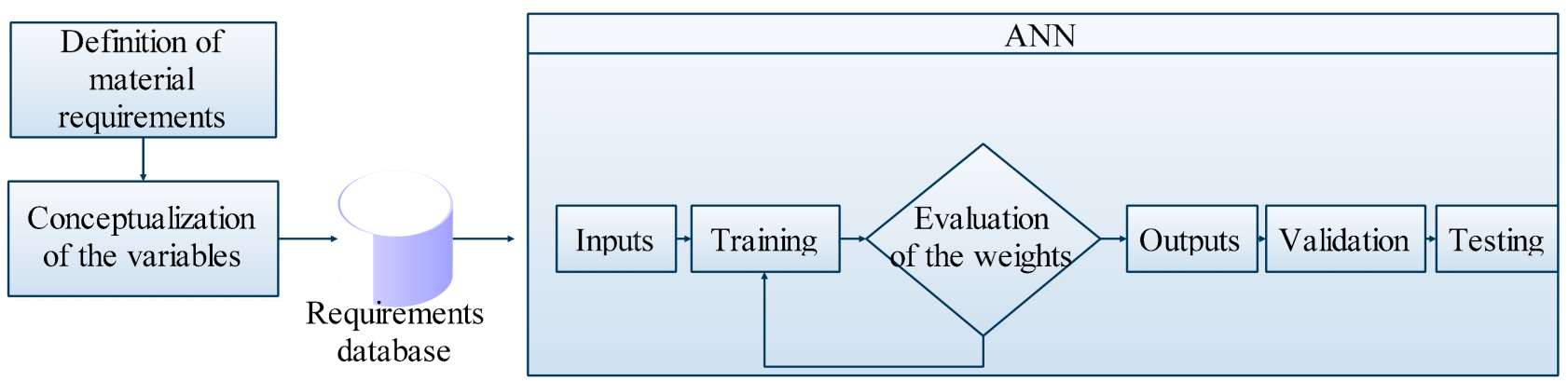

Figure 3. Diagram of the methodology for selecting the geomembrane. For the sake of clarity, each of the stages are described in the following sections.

\subsection{Definition of Material Requirements}

This section describes the main requirements that influence in the quality of highdensity polyethylene geomembranes used in the manufacture of lagoon biodigesters. The requirements were obtained through interviews. Such interviews were performed by experts with more than eight years of experience in the manufacture of biodigesters. The objective of these interviews is to obtain personalized information about events, experiences, and opinions about which parameters help to obtain the adequate quality that allow reducing defects in the manufacture of biodigesters. Mainly in the thermofusion process.

The requirements obtained from the interviews were the following: thickness (Tk), density (De), breaking strength (BS), tear resistance (TR), yield strength (YS), punching re- 
sistance (PR), composition (Co), type (T) and biodigester size (S). Relevant criteria obtained from interviews of each one of these requirements are described below.

1. Thickness (Tk). This feature refers to the width of the geomembranes. The ranges between which Tk oscillates are 0.75 to $3.0 \mathrm{~mm}$. It is necessary to have an adequate Tk that preferably facilitates the thermofusion process.

2. Density (De). This characteristic helps to know the flexibility in geomembranes. It also indicates if the material is suitable for direct exposure to the sun. For the construction of a biodigester, the De must be greater than $0.94 \mathrm{~g} / \mathrm{cm}^{3}$.

3. Breaking Strength (BS). The BS is the measure of force that a material opposes before a crack occurs. Common ranges in geomembranes are between 17 and $84 \mathrm{kN} / \mathrm{m}$. These values indicate the maximum tenseness of the geomembranes.

4. Tear Resistance (TR). Measurement of maximum strength of the geomembranes to resist the effects of tearing. Ranges for this feature are from 69 to $342 \mathrm{~N}$.

5. Yield Strength (YS). It is the point that indicates when a geomembrane undergoes a deformation when it is subjected to constant stress and temperature. Values range from 8 to $44 \mathrm{kN} / \mathrm{m}$.

6. Punching Resistance (PR). Maximum force to which the geomembrane is subjected before being perforated. Ranges are between 235 and $835 \mathrm{~N}$.

It is important to mention that the ranges from point 4 to 6 relative to resistance must be adequate for field management and for the thermofusion process.

7. Composition (Co). This feature refers to geomembrane components. Polyethylene geomembranes are manufactured with virgin polyethylene resins and carbon black. The geomembrane is composed of $97-98 \%$ polyethylene, leaving the rest for other components. It is important to have the correct Co that allows to guarantee a long duration, even under outdoor conditions. A geomembrane that is not in the correct percentage will decrease its resistance to UV rays and will start to get harder. If these percentages are not suitable, they tend to crystallize over time due to sun exposure, causing cracks and degradation of the geomembranes.

8. Geomembrane Type (T): This characteristic refers to whether the geomembrane is GM13 or nominal. The first fully comply with the American GM13 standard. While the nominal geomembranes do not comply with this requirement.

9. Biodigester Size (S): For this study, $\mathrm{S}$ was divided into two sizes: those that measure less than $80 \mathrm{~m}$ wide and $150 \mathrm{~m}$ long will be considered medium, and those that fulfill those measurements or more will be considered large.

In Table 1, we present the quality requirements of the geomembranes as well as the ranges they oscillate.

Table 1. Properties and ranges of the analyzed characteristics.

\begin{tabular}{cc}
\hline Properties of the Geomembrane & Range of Specifications \\
\hline Thickness (Tk) & $0.75-3.0 \mathrm{~mm}$ \\
\hline Density (De) & $>0.94 \mathrm{~g} / \mathrm{cm}^{3}$ \\
\hline Breaking Strength (BS) & $17-84 \mathrm{kN} / \mathrm{m}$ \\
\hline Tear Resistance (TR) & $69-342 \mathrm{~N}$ \\
\hline Yield Strength (YS) & $8-44 \mathrm{kN} / \mathrm{m}$ \\
\hline Punching Resistance (PR) & $235-835 \mathrm{~N}$ \\
\hline Composition (Co) & $97.5-98.0 \%$ \\
\hline Type (T) & GM13, Nominal \\
\hline Size (S) & Medium, Large \\
\hline
\end{tabular}




\subsection{Conceptualization of the Variables}

In this section, the selection of appropriate requirements that helped the ANN to classify is detailed. In this stage, the normalization of data, creation of multiple training data, and the establishment of desired outputs were carried out. The requirements selected that provided information for separation of geomembrane classes were Tk, BS, TR, PR, Co, $\mathrm{T}$ and S. Firstly, it was detected that variables De and YS were not independent since De was directly related with Tk, and variable YS was directly related to BS. For this reason, they were eliminated from the database.

For a more detailed analysis of the geomembranes, all possible ranges in which different geomembranes might vary among the Mexican market were studied. The database was established from seven different geomembrane vendors. The process to carry out the training cases is to discretize the selected requirements at different distances. In the case of Tk, the minimum value used in the manufacture of biodigesters is $0.65 \mathrm{~mm}$ and the maximum is $2.5 \mathrm{~mm}$. In our proposal, the ranges were discretized at 0.5 , giving Tk $\in\{0.65$, $0.7,0.75,0.8, \ldots, 2.5\}$. With these ranges, it is considered that 30 different values are found for the variable Tk. For the other characteristics, the ranges are: BS $\in\{20,21,22, \ldots, 84\}$ with 34 different values, $T R \in\{93,96,99, \ldots, 342\}$ with 90 different values, $P R \in\{240,252,264$, ..., 876\} with 320 different values, Co $\in\{97,97.5,98\}$ with 3 different values, and for $\mathrm{T}$ and $\mathrm{S} \in\{0,1\}$ with 2 different values, respectively. The foregoing is summarized in Table 2 .

Table 2. Ranges ${ }^{1}$ of each characteristic of the geomembranes.

\begin{tabular}{cccc}
\hline Characteristic (Unit) & Minimum & Maximum & Different Possible Values \\
\hline Tk $(\mathrm{mm})$ & 0.65 & 2.5 & 30 \\
\hline $\mathrm{BS}(\mathrm{kN} / \mathrm{m})$ & 20 & 84 & 34 \\
\hline $\mathrm{TR}(\mathrm{N})$ & 93 & 342 & 90 \\
\hline $\mathrm{PR}(\mathrm{N})$ & 240 & 876 & 320 \\
\hline Co $(\%)$ & 97 & 98 & 3 \\
\hline T $(\mathrm{GM} 13$, Nominal) & 0 & 1 & 2 \\
\hline S (Medium, Large) & 0 & 1 & 2 \\
\hline
\end{tabular}

${ }^{1}$ These ranges of the geomembranes were set up for the manufacture of lagoon biodigesters.

A total of 352,512,000 combinations of different geomembranes evaluated with the previous ranges were created. However, it is known that there are combinations that do not exist in the Mexican geomembrane market. For this reason, the number of possible and existing combinations was analyzed and, therefore, reduced to 21,612 possible combinations.

In order to validate the results of the interviews, the behavior of the geomembranes in their thermofusion process was evaluated. According to the interviews, if the thermofusion process is carried out correctly with the proper geomembrane, the number of defects decrease. To verify if the thermofusion process is carried out correctly, air pressure tests are carried out. In this case, the machinery that performs the thermofusion has the advantage that when the sealing is made, it leaves a canal in the middle where air under pressure can be introduced to perform air pressure tests (See Figure 4). This test detects air leaks in the geomembrane seals. It consists of measuring the air pressure with a manometer in joints where the respective canal exists. A time is granted between the initial measurement and the end of the pressure gauge. If a difference greater than 4 pounds per square inch (psi) is observed, it is considered as a possible brittle joint. The test is performed twice, so the possible brittle joints can be confirmed as failures. The process for conducting air pressure tests is described in Figure 5. 


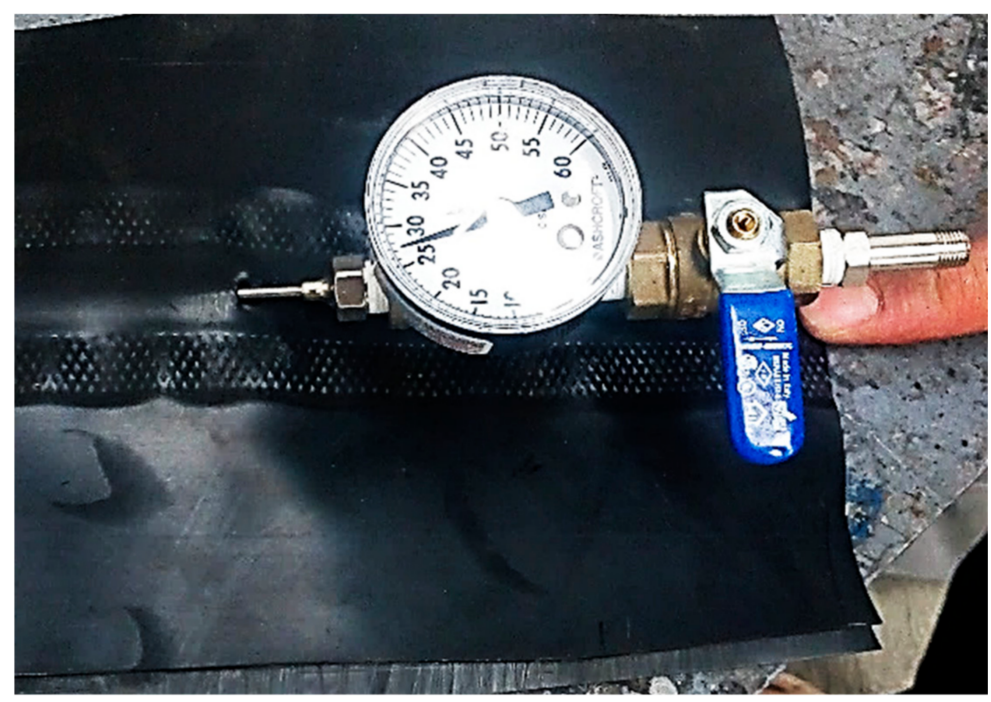

Figure 4. Air pressure test carried out in channel that leaves thermofusion machinery.

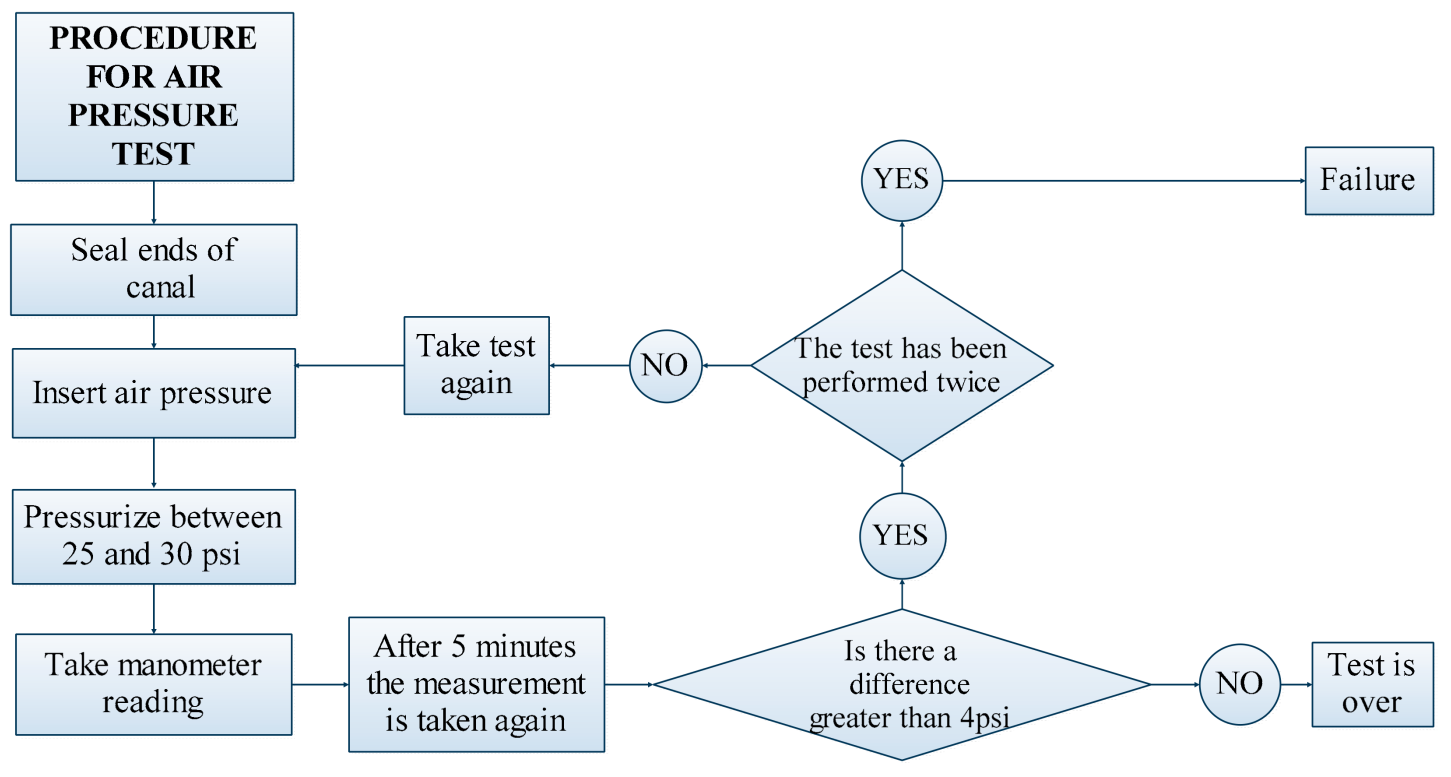

Figure 5. Diagram of the procedure for air pressure test.

When a given geomembrane has passed the air pressure test, it is considered that it has a correct performance in the thermofusion process, and therefore, it is appropriate as raw material for a biodigester. In addition to the above, it is desirable that the geomembranes selected must not increase manufacturing costs unnecessarily. In the market of geomembranes used for the construction of biodigesters, there are those of high resistance but which require more specialized machinery. With these parameters established, the appropriate geomembranes can be represented. Tables 3-5 present the ranges of each characteristic considered appropriate following the quality criteria mentioned.

With the ranges shown in Tables 3-5, it is inferred that there are 14 appropriate values for Tk, 10 for BS, 16 for TR, 15 for PR, 7 for Co and 2 for T and S, respectively. These values establish the existing combinations of appropriate geomembranes with a total of 2708 different combinations. This leads to the conclusion that a total of 18,904 geomembrane combinations are considered inappropriate for the manufacture of a biodigester. 
Table 3. Suitable ranges of geomembrane characteristics.

\begin{tabular}{ccccc}
\hline Characteristic & Minimum & Maximum & $\begin{array}{c}\text { Range of } \\
\text { Specifications }\end{array}$ & Values \\
\hline Tk $(\mathrm{mm})$ & 1.4 & 1.5 & 0.05 & 3 \\
\hline BS (kN/m) & 44 & 47 & 1 & 4 \\
\hline TR (N) & 188 & 200 & 3 & 5 \\
\hline PR (N) & 500 & 608 & 12 & 3 \\
\hline Co (\%) & 97 & 98 & 1 & 1 \\
\hline T (GM13, Nominal) & 1 & 1 & 1 & 1 \\
\hline S (Medium, Large) & 0 & 0 & 0.5 \\
\hline
\end{tabular}

Table 4. Suitable ranges of geomembrane characteristics.

\begin{tabular}{ccccc}
\hline Characteristic & Minimum & Maximum & $\begin{array}{c}\text { Range of } \\
\text { Specifications }\end{array}$ & Values \\
\hline Tk $(\mathrm{mm})$ & 1.8 & 2 & 0.05 & 5 \\
\hline BS $(\mathrm{kN} / \mathrm{m})$ & 63 & 64 & 1 & 2 \\
\hline TR $(\mathrm{N})$ & 269 & 287 & 3 & 7 \\
\hline PR $(\mathrm{N})$ & 716 & 716 & 1 & 1 \\
\hline Co $(\%)$ & 97.5 & 98 & 0.5 & 2 \\
\hline T (GM13, Nominal) & 1 & 1 & 1 & 1 \\
\hline S (Medium, Large) & 1 & 1 & 1 & 1 \\
\hline
\end{tabular}

Table 5. Suitable ranges of geomembrane characteristics.

\begin{tabular}{ccccc}
\hline Characteristic & Minimum & Maximum & $\begin{array}{c}\text { Range of } \\
\text { Specifications }\end{array}$ & Values \\
\hline Tk $(\mathrm{mm})$ & 2.25 & 2.5 & 0.05 & 6 \\
\hline BS $(\mathrm{kN} / \mathrm{m})$ & 81 & 84 & 1 & 4 \\
\hline TR $(\mathrm{N})$ & 333 & 342 & 3 & 4 \\
\hline PR $(\mathrm{N})$ & 840 & 876 & 12 & 4 \\
\hline Co $(\%)$ & 97.5 & 98 & 0.5 & 2 \\
\hline T (GM13, Nominal) & 1 & 1 & 1 & 1 \\
\hline S (Medium, Large) & 1 & 1 & 1 & \\
\hline
\end{tabular}

\subsection{Development of a Back Propagation ANN}

ANNs, based on the structure of the nervous system, are capable of learning from experience and have special characteristics for solving classification and prediction problems. ANNs consist of nodes with interconnecting synaptic and activation links. The weight given to different links decides the critical effect of the different input pairs on the outputs. Each neuron holds three important elements that are: connecting links (weights), adder (summing agent) and an activation function, which control the amplitude of the output [24]. In the proposed method, the characteristics of the geomembranes mentioned in Section 2.2 are the inputs in an ANN. Additionally, we have one output $\{1,0\}$ for those appropriate and inappropriate geomembranes, respectively.

For different computational and modeling tasks, different types of neural networks and their structures can be applied and recommended [25]. In our approach, the method of Back Propagation (BP) was chosen to train the ANN. The BP neural networks were proposed by Rumelhart, D.E. and McCelland, J.L. These networks are one of the most 
widely used neural network models. The development of the BP neural network is relatively mature and is easy to implement [26]. The method begins by computing the ANN output with the current weight values. At each iteration, the weights are updated in a way that the actual network output is closer and closer to the target. In the processing units of feedforward, inputs $X_{i}$ are multiplied by weights $W_{j i}$ for a hidden node $h_{j}$; summation of all the $W_{j i} \times X_{i}$ is then added to a bias value $\theta_{j i}$ and finally operated by a suitable transfer function $(f)$. The operation can be written as in Equation (1).

$$
h_{j}=f\left(\sum W_{j i} X_{i}+\theta_{j i}\right) .
$$

In the process of learning, the error is calculated by Equation (2). The predicted output in relation to the actual output is backpropagated to adjust all the weight and bias values.

$$
E=\frac{1}{n} \sum_{i=1}^{n}\left(Y_{i}-O_{i}\right)^{2}
$$

where $Y_{i}$ is the predicted output of the network and $O_{i}$ is the expected output.

For development of the proposed ANN, software MATLAB ${ }^{\circledR}$ was used. The inputs introduced to train the network were properties of the geomembrane, the output consisted of giving a value of 1 if the geomembrane is suitable for construction and 0 if it is the opposite. The ANN had 3 stages: training, validation, and testing. In the training stage, the weights were adjusted automatically until the desired result is achieved. In the second stage, the model was validated to test the performance of the network, the validation and testing process was carried out using a different data set than in training. As it was described in Section 2.2, a total of 21,612 training patterns were included in the dataset. The proportion of the patterns for each ANN evaluation stage was $70 \%$ for training, $15 \%$ for validation and $15 \%$ for testing. The selection of the samples was performed randomly.

\section{Results}

In this section, an ANN with a multilayer feeding network structure and supervised learning is proposed. The optimal architecture for the ANN was chosen following the mean squared error (MSE) values. The lower the value, the better the fit of the model. First, an evaluation was carried out with different learning algorithms that exist for BP-ANNs. Parameters that were kept constant were a non-linear transfer function "logsig", 10 neurons in the hidden layer, and 150 epochs. Each algorithm was trained five times to obtain its average. As shown in Table 6, trainlm was the best acceptable learning algorithm, whose training time was shorter with an MSE of 0.00457.

Table 6. Influence of BP algorithms.

\begin{tabular}{lccc}
\hline \multicolumn{1}{c}{ Algorithms } & MSE & Training Time (s) & Epoch \\
\hline Gradient Descent, (Traingd) & 0.0710 & 3 & 84 \\
\hline Gradient Descent with Momentum, (Traingdm) & 0.0410 & 4 & 97 \\
\hline Resilient Backpropagation, (Trainrp) & 0.0110 & 5 & 112 \\
\hline $\begin{array}{l}\text { Variable Learning Rate Gradient Descent, } \\
\text { (Traingdx) }\end{array}$ & 0.0830 & 5 & 145 \\
\hline Fletcher-Powell Conjugate Gradient, (Traincgf) & 0.0370 & 4 & 116 \\
\hline Polak-Ribiére Conjugate Gradient, (Traincgp) & 0.0072 & 3 & 84 \\
\hline Scaled Conjugate Gradient, (Trainscg) & 0.0240 & 4 & 146 \\
\hline BFGS Quasi-Newton, (Trainbfg) & 0.0130 & 5 & 134 \\
\hline One Step Secant, (Trainoss) & 0.0084 & 4 & 144 \\
\hline Levenberg-Marquardt, (Trainlm) & 0.0045 & 3 & 76 \\
\hline
\end{tabular}


Secondly, the different transfer functions in the hidden layer were analyzed. The ANN was trained 20 times for each of the transfer functions. The best results are displayed in Table 7. The logsig transfer function has the best performance, although it is not very significant compared to the tansig function. Finally, the number of neurons in the hidden layer was determined by testing a different number of neurons in the hidden layer. Specifically, in the range of $\{6,7,8, \ldots, 18\}$ neurons. Each of the values in this range was trained five times, in order to obtain its average. The results are shown in Table 8. As it can be seen in this table, the best MSE is obtained with eight neurons in the hidden layer. After that, a non-linear transfer function "logsig" and a Levenberg-Marquardt algorithm (trainlm) were selected. With this process, the best BP-ANN was established.

Table 7. Influence of transfer functions.

\begin{tabular}{cccc}
\hline Transfer Functions & MSE & Training Time (s) & Epoch \\
\hline Purely & 0.0051 & 3 & 53 \\
\hline Tansig & 0.0008 & 4 & 77 \\
\hline Logsig & 0.0004 & 2 & 82 \\
\hline
\end{tabular}

Table 8. Influence of the number of neurons in the hidden layer.

\begin{tabular}{cccc}
\hline Neurons & MSE & Training Time (s) & Epoch \\
\hline 6 & 0.0051 & 3 & 85 \\
\hline 7 & 0.0061 & 4 & 98 \\
\hline 8 & 0.0003 & 2 & 65 \\
\hline 9 & 0.0058 & 2 & 74 \\
\hline 10 & 0.0066 & 1 & 87 \\
\hline 11 & 0.0067 & 2 & 122 \\
\hline 12 & 0.0144 & 1 & 101 \\
\hline 13 & 0.0054 & 1 & 136 \\
\hline 14 & 0.0133 & 3 & 85 \\
\hline 15 & 0.0064 & 4 & 86 \\
\hline 16 & 0.0562 & 1 & 98 \\
\hline 17 & 0.0142 & 1 & 150 \\
\hline 18 & 0.0101 & 1 & 150 \\
\hline
\end{tabular}

Figure 6 shows the architecture of the ANN used, which consists of a backpropagation multilayer perceptron neural network with supervised learning, which consists of seven inputs, eight hidden layer neurons and one output.

With the established parameters, ANN training was carried out. It was found that after 57 epochs of training, the desired outputs were obtained. In Figure 7, the performance of the neural network is observed. The evolution of MSE is shown for training, validation, and test sets. It is observed with emphasis that in epoch 52, the best scenario was obtained in the validation set, which was 0.000304 .

The results obtained in the classification tests are presented in Tables 9-11, for training, validation, and testing, respectively. Each one of these tables originated from the corresponding confusion matrices.

It is observed that only one datum was incorrectly classified in the ANN training stage. In the validation stage, one datum was misclassified and, in the test stage classification there were zero errors. With these results, we have a total of 2 misclassified samples and 21,610 correctly classified samples, giving a total success rate of $99.9 \%$. 


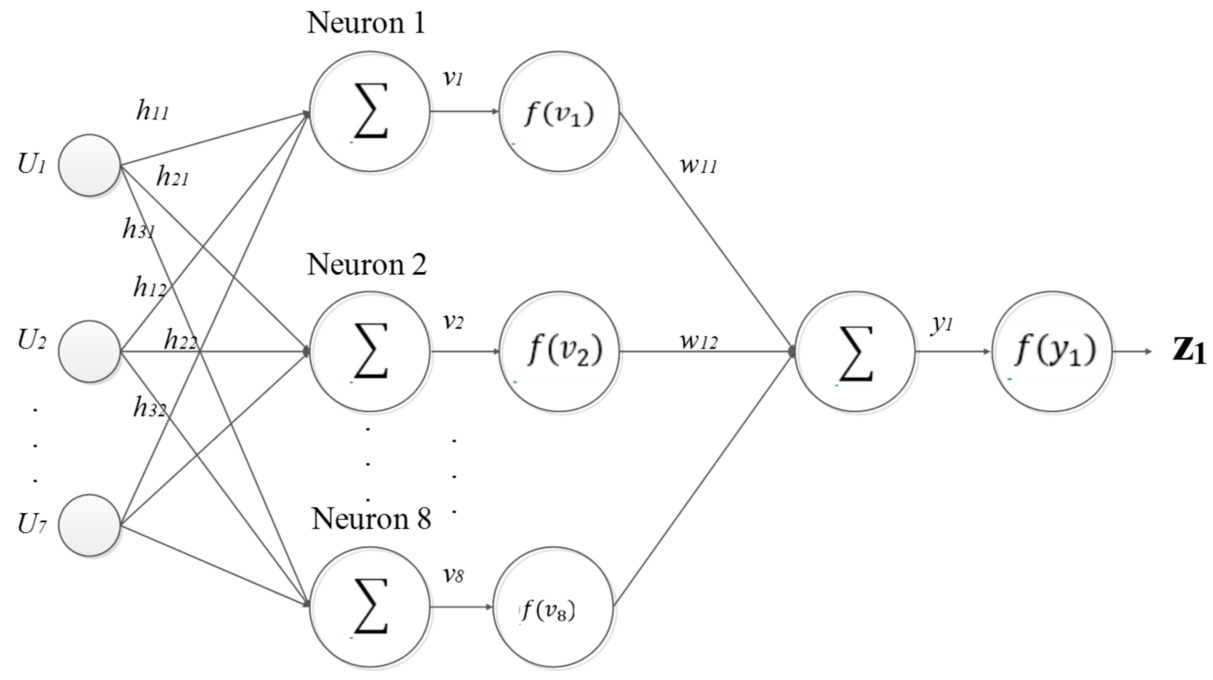

Figure 6. Proposed neural network architecture.

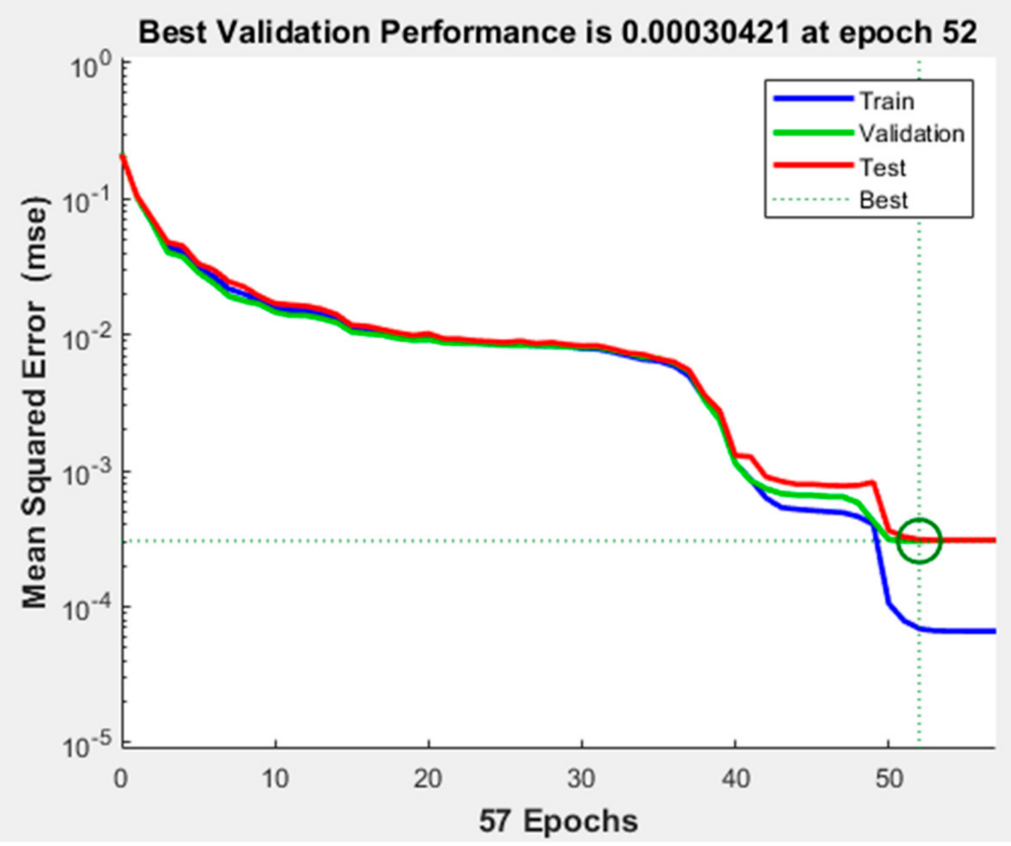

Figure 7. Evolution of the neural network MSE.

Table 9. Results of classifications for training stage.

\begin{tabular}{cccc}
\hline Class & $\begin{array}{c}\text { Correct } \\
\text { Classifications }\end{array}$ & $\begin{array}{c}\text { Wrong } \\
\text { Classifications }\end{array}$ & $\begin{array}{c}\% \\
\text { of Success }\end{array}$ \\
\hline $\begin{array}{c}\text { Unsuitable } \\
\text { geomembrane }\end{array}$ & 13,278 & 1 & 99.9 \\
\hline $\begin{array}{c}\text { Appropriate } \\
\text { geomembrane }\end{array}$ & 1849 & 0 & 100 \\
\hline Overall & 15,127 & 1 & 99.9 \\
\hline
\end{tabular}


Table 10. Results of classifications for validation stage.

\begin{tabular}{cccc}
\hline Class & $\begin{array}{c}\text { Correct } \\
\text { Classifications }\end{array}$ & $\begin{array}{c}\text { Wrong } \\
\text { Classifications }\end{array}$ & $\begin{array}{c}\% \\
\text { of Success }\end{array}$ \\
\hline $\begin{array}{c}\text { Unsuitable } \\
\text { geomembrane }\end{array}$ & 2800 & 1 & 99.9 \\
\hline $\begin{array}{c}\text { Appropriate } \\
\text { geomembrane }\end{array}$ & 441 & 0 & 100 \\
\hline Overall & 3241 & 1 & 99.9 \\
\hline
\end{tabular}

Table 11. Results of classifications for tests stage.

\begin{tabular}{cccc}
\hline Class & $\begin{array}{c}\text { Correct } \\
\text { Classifications }\end{array}$ & $\begin{array}{c}\text { Wrong } \\
\text { Classifications }\end{array}$ & $\begin{array}{c}\% \\
\text { of Success }\end{array}$ \\
\hline $\begin{array}{c}\text { Unsuitable } \\
\text { geomembrane }\end{array}$ & 2824 & 0 & 100 \\
\hline $\begin{array}{c}\text { Appropriate } \\
\text { geomembrane }\end{array}$ & 418 & 0 & 100 \\
\hline Overall & 3242 & 0 & 100 \\
\hline
\end{tabular}

\section{Conclusions}

In this article, an approach for the evaluation of the geomembranes used as raw material for the manufacturing process of a given biodigester is proposed. First, considering that in Mexican companies, the evaluation of a given geomembrane is based on the experience of the workers, we synthesize such experience in a database through interviews (qualitative evaluations). Variables obtained from the interviews that helped the analysis of the geomembranes were thickness (Tk), breaking strength (BS), tear resistance (TR), punching resistance (PR), composition (Co), type (T) and biodigester size (S). After that, we validate the qualitative results through a quantitative physical test (air pressure test) during the thermofusion process that confirms if a geomembrane is suitable to be used as raw material. Additionally, in order to automate the evaluation, an ANN is proposed as a two-class classifier: appropriate and not-appropriate. The results demonstrated that the ANN with logsig activation function, trainslm learning algorithm and a 7-8-1 topology, obtained the accuracy of $99.9 \%$ for the classification of geomembranes. Unlike existing methods, our approach achieves the dual goals of extracting features, validating them, and designing the classifier simultaneously. Our method provides a practical tool for helping workers to evaluate raw material when high performance, quality, and safety are required.

Author Contributions: Conceptualization and methodology, R.B.-S. and R.A.L.-M.; software, R.C.-M.; validation R.A.L.-M., R.B.-S. and R.C.-M.; formal analysis R.C.-M.; investigation, R.C.-M.; resources, R.A.L.-M., R.B.-S. and R.C.-M.; data curation R.A.L.-M., R.B.-S. and R.C.-M.; writing, review and editing, R.A.L.-M., R.B.-S. and R.C.-M. All authors have read and agreed to the published version of the manuscript.

Funding: The work presented in this paper has not received external funding.

Institutional Review Board Statement: Not applicable.

Informed Consent Statement: Not applicable.

Acknowledgments: The authors would like to thank the University of Guanajuato for the financial support. In addition, Camarena-Martinez would like to thank the Mexican CONACyT for the financial support provided.

Conflicts of Interest: The authors declare no conflict of interest. 


\section{References}

1. Awogbemi, O.; Kallon, D.V.V. An Overview of the Classification, Production and Utilization of Biofuels for Internal Combustion Engine Applications. Energies 2021, 14, 5687. [CrossRef]

2. Hernández, M.; Sierra, J. The Potential of the Biodigester as a Useful Tool in Coffee Farms. Appl. Sci. 2021, 11, 6884. [CrossRef]

3. Lombardi, L.; Mendecka, B. Solar Integrated Anaerobic Digester: Energy Savings and Economics. Energies 2020, $13,4292$. [CrossRef]

4. American Society for Testing and Materials (ASTM International). Norm ASTM D4439-20 Standard Terminology for Geosynthetics; ASTM International: West Conshohocken, PA, USA, 2020.

5. Lavoie, F.L.; Valentin, C.A. HDPE Geomembranes for Environmental Protection: Two Case Studies. Sustainability $2020,12,8682$. [CrossRef]

6. Shared Risk Trust. General Diagnosis of the Situation of Biodigestion Systems in Mexico; Federal Bureau of Agriculture, Animal Breeding and Rural Development: Mexico City, Mexico, 2010.

7. Cetiner, I.; Var, A.A. Classification of Knot Defect Types Using Wavelets and KNN. Elektron. Ir Elektrotechnika 2016, 22, 67-72. [CrossRef]

8. Lizarraga-Morales, R.A.; Correa-Tome, F.E.; Sanchez-Yanez, R.E.; Cepeda-Negrete, J. On the Use of Binary Features in a Rule-Based Approach for Defect Detection on Patterned Textiles. IEEE Access 2019, 7, 18042-18049. [CrossRef]

9. Pervaiz, S.; Ul-Qayyum, Z. A Systematic Literature Review on Particle Swarm Optimization Techniques for Medical Diseases Detection. Comput. Math. Methods Med. 2021, 2021, 10. [CrossRef] [PubMed]

10. Amor, N.; Noman, M.T. Classification of Textile Polymer Composites: Recent Trends and Challenges. Polymers 2021, 13, 2592. [CrossRef] [PubMed]

11. De Paula, L.A.; Eckert, K.B.; Guismín, G. Clasificación de hojas de té al ingreso del proceso de secado mediante redes neuronales con datos supervisados y no supervisados. In Proceedings of the Congreso Argentino de AgroInformática, Buenos Aires, Argentina, 3-7 September 2018; Argentine Society of Informatics and Operations Research CABA: Buenos Aires, Argentine, 2018; p. 76.

12. Mellit, A.; Benghanem, M. Design of a Novel Remote Monitoring System for Smart Greenhouses Using the Internet of Things and Deep Convolutional Neural Networks. Energies 2021, 14, 5045. [CrossRef]

13. Essid, O.; Laga, H. Automatic detection, and classification of manufacturing defects in metal boxes using deep neural networks. PLoS ONE 2018, 13, e0203192. [CrossRef] [PubMed]

14. Gómez, J.; Sánchez, J. Application of neural networks in the classification of clays. J. EIA 2012, 17, $183-191$.

15. Singh, V.; Tathavadkar, V. Predicting the performance of submerged arc furnace with varied raw material combinations using artificial neural network. J. Mater. Process. Technol. 2007, 183, 111-116. [CrossRef]

16. Zhu, N.; Wang, K. Application of artificial neural networks to predict multiple quality of dry-cured ham based on protein degradation. Food Chem. 2021, 344, 115-124. [CrossRef] [PubMed]

17. Kulisz, M.; Kujawska, J. Forecasting Water Quality Index in Groundwater Using Artificial Neural Network. Energies 2021, 14, 5875. [CrossRef]

18. Kumari, S.; Rakesh, K. Leakage Rate Prediction through Composite Liner due to Geomembrane Defect using Neural Network. J. Geotech. Eng. 2019, 6, 8-17.

19. Abuel-Naga, H.M.; Bouazza, A. Numerical experiment-artificial intelligence approach to develop empirical equations for predicting leakage rates through GM/GCL composite liners. Geotext. Geomembr. 2014, 42, 236-245. [CrossRef]

20. Mandal, A.; Cho, H. ANN Prediction of Performance and Emissions of CI Engine Using Biogas Flow Variation. Energies 2021, 14, 2910. [CrossRef]

21. Frankowski, J.; Zaborowicz, M. Biological Waste Management in the Case of a Pandemic Emergency and Other Natural Disasters. Determination of Bioenergy Production from Floricultural Waste and Modeling of Methane Production Using Deep Neural Modeling Methods. Energies 2020, 13, 3014. [CrossRef]

22. Idris, M.; Abiola, O. Performance evaluation of three different-shaped bio-digesters for biogas production and optimization by artificial neural network integrated with genetic algorithm. Sustain. Energy Technol. Assess. 2018, 26, 116-124.

23. Tabarquino, V.H.; González, L.O. Estimation of the volume of a balloon-type Biodigester using artificial neural networks. Tech. Informant 2016, 80, 41-48.

24. Veerendra, S.; Banerjee, P.K. Artificial Neural Network Modeling of Ball Mill Grinding Process. J. Powder Metall. 2013, 2, 106-117.

25. Arora, V.; Mahla, S.K. Intervention of Artificial Neural Network with an Improved Activation Function to Predict the Performance and Emission Characteristics of a Biogas Powered Dual Fuel Engine. Electronics 2021, 10, 584. [CrossRef]

26. He, Y.; Gong, Z. Inland Reservoir Water Quality Inversion and Eutrophication Evaluation Using BP Neural Network and Remote Sensing Imagery: A Case Study of Dashahe Reservoir. Water 2021, 13, 2844. [CrossRef] 